\title{
YVES CLAVARON, Francophonie, postcolonialisme et mondialisation
}

\section{Roberto Ferraroni}

\section{(2) OpenEdition}

\section{Journals}

\section{Edizione digitale}

URL: https://journals.openedition.org/studifrancesi/32328

DOI: 10.4000/studifrancesi.32328

ISSN: 2421-5856

\section{Editore}

Rosenberg \& Sellier

\section{Edizione cartacea}

Data di pubblicazione: 1 août 2020

Paginazione: 444-445

ISSN: 0039-2944

\section{Notizia bibliografica digitale}

Roberto Ferraroni, «YVES CLAVARon, Francophonie, postcolonialisme et mondialisation», Studi Francesi [Online], 191 (LXIV | II) | 2020, online dal 01 septembre 2020, consultato il 18 septembre 2021. URL: http://journals.openedition.org/studifrancesi/32328; DOI: https://doi.org/10.4000/studifrancesi. 32328

Questo documento è stato generato automaticamente il 18 septembre 2021.

\section{(c)}

Studi Francesi è distribuita con Licenza Creative Commons Attribuzione - Non commerciale - Non opere derivate 4.0 Internazionale. 


\title{
YVES CLAVARON, Francophonie, postcolonialisme et mondialisation
}

\author{
Roberto Ferraroni
}

\section{NOTIZIA}

YVES CLAVARON, Francophonie, postcolonialisme et mondialisation, Paris, Classiques Garnier, 2018, $258 \mathrm{pp}$.

1 Con questo saggio, Yves Clavaron vuole tracciare un panorama ben definito del mondo della letteratura in lingua francese nata e sviluppatasi al di fuori dei confini della Francia esagonale. Come si evince chiaramente già a partire dal titolo, il concetto di francofonia, che Clavaron prende come punto di partenza per il suo studio, viene intrecciato a quello di postcolonialismo e mondializzazione. L'autore studia ed esplicita abilmente i meccanismi e le dinamiche che ne regolano le interrelazioni reciproche, i modi in cui gli studi francofoni riescono di fatto a integrarsi con gli studi postcoloniali. Parte naturalmente dalla lingua francese, ma allarga il campo di indagine anche ad altre aree linguistiche.

2 Il volume si apre con un'introduzione di poche pagine in cui Clavaron anticipa al lettore, in modo rapido ma ben dettagliato, la struttura dell'opera: un saggio diviso in cinque sezioni, ognuna delle quali dedicata ad un argomento specifico. Lo schema di ogni parte, caratterizzato da una suddivisione in capitoli e paragrafi, si rispecchia nelle altre; a chiudere ogni capitolo il lettore trova una conclusione che recupera le fila del discorso tracciato dall'autore. Le ultime pagine sono dedicate a una conclusione generale che aiuta a raccogliere le idee e a collegare tra di loro tutte le pagine dell'opera.

La prima sezione cerca di mettere in luce i limiti di ciò che può rappresentare «l'univers francophone au sein de la mondialisation, qu'il est légitimement possible d'assimiler à une occidentalisation» (p. 13). Mettendo in relazione, nel primo capitolo, la francofonia con gli studi postcoloniali e il mondo anglosassone, si apre in maniera 
evidente una prospettiva rivolta verso il concetto di "post-francofonia". Si continua in questa direzione anche nel secondo capitolo, con l'introduzione di una variante della nozione di letteratura mondiale: la "Littérature-monde", la World literature, che permette di riaccendere la Weltliteratur di Goethe, una letteratura "voyageuse" in sintonia con il mondo.

4 La seconda sezione abbandona, almeno apparentemente, il tema della letteratura in senso stretto per concentrarsi maggiormente su quei cambiamenti sociali e culturali che hanno gettato le basi per la nascita di un tipo di letteratura che finalmente si distacca dai canoni della tradizione della "vecchia Europa colonizzatrice". Anche in questo caso Clavaron non si limita alla sola sfera linguistica francese, ma nello specifico va a toccare anche il mondo latino-americano. Analizza quei principi di una mondializzazione caratterizzata soprattutto da mobilità e scambi: «flux, diasporas, hybridations et globalisation, par laquelle l'État-nation se déspatialise en développant des stratégies transnationales» (p. 14).

5 La terza e la quarta sezione, «Traversées océaniques» e «Traversées historiques», sono in qualche modo legate tra loro, come già si evince dai due titoli speculari. Infatti da un lato la terza parte racconta come i viaggi transoceanici hanno iniziato a mettere in atto una sorta di inversione di marcia che porta in sé il segnale di come l'autorità imperiale sia stata sovvertita "par le contre-récit de voyage, dans lequel le voyageur à l'envers, qu'il soit francophone ou anglophone inverse la trajectoire de centre à périphérie et cesse de faire du voyage un trajet à sens unique» (p. 14); dall'altro lato invece, la quarta parte permette di passare dalla categoria dello spazio a quella del tempo e di analizzare la nascita «des études subalternistes conçues dans la contestation de l'eurochronologie» (p. 15) e del modello storiografico occidentale. In entrambe le sezioni, l'autore prende come esempi focali della propria argomentazione gli scritti di autori indiani, che hanno dato voce a un popolo colonizzato dagli Inglesi.

6 La quinta e ultima sezione tocca tematiche di estrema attualità: infatti Clavaron prova a estendere la nozione di mondo all'ecosfera e prova a rivisitare la mondializzazione attraverso il filtro delle problematiche ecologiste. Ne scaturisce un'interessante analisi dei corretti comportamenti, della giusta poetica di vita da scegliere per salvaguardare il nostro pianeta, rispettando i luoghi e gli esseri, umani e animali, che lo abitano.

7 Scritto in un linguaggio chiaro e fruibile da parte di lettori anche non esperti, Clavaron traccia un interessante quadro che illustra la direzione presa dalla, per lui, fuletteratura-francofona, abbozzando spazi letterari transnazionali inediti. 